\title{
Communication: Where Evolutionary Linguistics Went Wrong
}

\section{Sergio Balari}

Departament de Filologia Catalana

Centre de Lingüística Teòrica

Universitat Autònoma de Barcelona

Bellaterra, Barcelona, Spain

Sergi.Balari@uab.cat

\section{Guillermo Lorenzo}

Departamento de Filología Española

Universidad de Oviedo

Oviedo, Spain

glorenzo@uniovi.es

\begin{abstract}
In this article we offer a detailed assessment of current approaches to the origins of language, with a special focus on their historical and theoretical underpinnings. It is a widely accepted view within evolutionary linguistics that an account of the emergence of human language necessarily involves paying special attention to its communicative function and its relation to other animal communication systems. Ever since Darwin, some variant of this view has constituted the mainstream version in evolutionary linguistics; however, it is our contention in this article that this approach is seriously flawed, and that "animal communication" does not constitute a natural kind on which a sound theoretical model can be built. As a consequence, we argue that this communicative perspective is better abandoned in favor of a structural/formal approach based on the notion of homology, and that some interesting and unexpected similarities may be found by applying this venerable comparative method founded in the 19th century by Richard Owen.
\end{abstract}

\section{Keywords}

communication, evolution of language, functions of organic structures, homology 
Communication is an evolved organic function to the same extent as, for example, blood circulation and locomotion are evolved organic functions. Language, the communication system (CS) specifically used by human beings, is therefore a particular instance resulting from the evolution of the communicative function. These two statements, commonly seen as unproblematic, conform the underpinnings on which the most generally accepted explanations for the evolutionary origins of language are constructed. Our first goal, to which we devote the first section of this article, is to argue that these claims do not make any theoretical sense and therefore most contemporary theoretical approaches to the evolutionary study of language do not make any theoretical sense either. The idea that language is not a CS, one of the main lines of attack to confute these approaches, is not new. Our argument, however, does not fundamentally rely on this but instead rests mainly on the idea that none of the so-called "animal communication systems" is really an animal communication system (henceforth ACS). The notion "animal communication," while perfectly intelligible and even useful for nontheoretical purposes, does not refer to anything that may legitimately be considered as a true natural kind. Hence, it is neither a notion on which any theoretical approach to language can possibly be based nor, logically, any explanation of its evolutionary origins. We shall use the term "communicative fallacy" to designate the collection of assumptions expressed in the theories summarized above.

However, this work also has a second goal, closely connected to the first. Thus, just as we have argued that language is not an evolved version of the communicative function, in the second section we will argue that language, like any other organic system, is neither an evolved form nor an evolutionary innovative way of performing any specific function. The assumption that language, or any other organic system, is an object of this kind will be classified as an instance of the "functionalist fallacy." It is also one of our goals to show that the evolutionary study of language is not explained by the functionalist fallacy. The first step to unveiling this fallacy consists in applying the very same argument that we have applied to the case of the communicative function to any element $f$ of the set $\mathrm{F}$ of organic functions in order to show that none of these varieties actually refers to a natural kind. This is the reason why evolutionary explanations must be based on the identification of homologues of the studied organic systems or of the components of such systems where their complexity calls for such a strategy. Recall that the notion of "homology" has always been insensitive to any kind of functional consideration, and that its more recent reformulations are fundamentally based on the existence of similar developmental resources in the process of establishing the individuality of the implied structures. Only a few contemporary exceptions exist where an attempt is made to extend the notion of homology to functions and/or behaviors, but, as we will argue below, none of these attempts actually succeeds in their effort of constructing a consistent definition of "behavioral homology."

In conformity with the preceding discussion, we will conclude that the communicative perspective is better abandoned in favor of a structural/formal approach based on the classical notion of homology, and that language must be described as an organic system whose evolutionary explanation needs to be grounded on the establishment of a true base of homologous systems. Language is not a modified form of performing any function $f$; nor in fact is it the modified version of some organic structure $s$ either. Rather, language is the structure in which a developmental system D is expressed, itself a modified variety of an ancestral system, which is the origin of many other developmental systems $d$, each responsible for the implantation in different organisms of different organic structures, both from the functional as well as formal point of view. As we will point out toward the end of this article, a number of interesting structural similarities may be identified between language and other cognitive systems in other species by applying this venerable comparative method founded in the 19th century by Richard Owen.

\section{Against the Communicative Fallacy}

To be able to ward off an environmental threat or attract a potential sexual partner may be a direct consequence of being able to receive or emit some kind of signal. It is therefore hard to question the advantages of communication over oblivion. But communication can also be dangerous-one who cries to alert may immediately or directly be exposed to the threat in question; one who trusts a display may eventually find out that it was a fraud, or, even worse, a deadly trap. Be this as it may, however, what all this boils down to is that minimal differences in the performance of some communicative act may mark the difference between leaving more or less offspring, between surviving or succumbing, depending on a subtle balance between the assumed risk and the derived advantages. In a nutshell, communication appears to be a kind of natural activity perfectly adjusted to the basic principle of selection between competing variants on which the Darwinian game of organic evolution is based.

It is thus understandable that communication is easily seen as an evolved organic function with a high adaptive value and therefore as ubiquitous but highly diversified, given the diversity of selective pressures it supposedly had to respond to in different environmental and populational situations (Smith 1977; Hauser 1997). Nor it is surprising that language is equally easily seen as a particular form resulting from the evolution of the communicative function (Eibl-Eibesfeldt 1984: ch. 6). However, both the idea that communication is an evolved organic function and that language represents the evolution in a particular direction of this function are totally 
unwarranted - both conform what we have termed above as the communicative fallacy.

\section{The Communicative Model: Two Variations on the Same Fallacy}

The communicative fallacy underlies most conceptions, both intuitive and theoretically informed, of language. It is highly difficult to identify some example where one can perceive in a clear and unequivocal manner that its influence is not present in some way or another. As for the explanatory models of the origins of language developed after the basic principles of evolutionary theory were established, and which will be the main focus of attention of this work, the communicative fallacy also appears as the common ingredient in most of them, despite the varying degrees of importance attributed to the communicative factor in their recipe to explain the existence of language.

The application of the theory of natural selection to the case of language, as suggested by Darwin in The Descent of Man ([1871] 1879), could be seen as an early, but already quite elaborated, incarnation of a first family of models that sees in language nothing else but a modified variety of an ancestral system of communication. Given the context of its inception, we can say that this model is a manifestation of the "Darwinian version" of the communicative fallacy. ${ }^{1}$ This model of evolutionary explanation of language based on the Darwinian version of the communicative fallacy is still kept alive, especially by the work of some researchers, who strive to find the connection between the most challenging formal features of human language and the gestures and calls of primates. ${ }^{2}$

The second family of models instantiates a much more sophisticated variety of the communicative fallacy, typically observed in approaches, which in some way or the other adopt a critical stance toward the Darwinian orthodoxy. Perhaps the most illustrative and influential proposal along these lines is the main representative of what we shall call, for reasons to be made clear presently, the "Hauserian version" of the communicative fallacy, which was developed by Hauser et al. (2002).

A crucial aspect of Hauser et al.'s paper (2002) is its careful distinction between the "communicative" vs. "computational" aspects of language (p. 1569): It makes sense to speak of language qua CS when we study it from the point of view of its usefulness as a medium to externalize certain types of internal mental representations; in addition, however, language must also be studied abstracting away from the mechanisms used for the externalization of these representations and from the systems responsible for their elaboration, in which case language is reduced to a mere computational system in charge of generating "bridge expressions," themselves internal, between these mechanisms and systems. According to the terminology proposed by Hauser, Chomsky, and Fitch (henceforth HCF), we study language in a "broad sense" when we adopt the communicative point of view; whereas we study language in a "narrow sense" when we adopt the computational point of view. In the narrow sense, then, language is not a CS; but it $i$ s one in the broader sense. In any event, the computational system - or Faculty of Language in the Narrow sense (FLN)is one more piece of language as a CS or Faculty of Language in the Broad sense (FLB). One of HCF's main claims is that the computational system used by FLB appears to be unique, with no equivalent in other aspects of animal cognition.

$\mathrm{HCF}$ is often read and interpreted as a defense of the specifically human and linguistic character of FLN, the computational aspect of language. This interpretation, we believe, is correct; but only partly. HCF also, and perhaps above all, is a defense of the singularity of language qua CS and, in this sense, a particular application of the research program on the evolution of the communicative function developed by Hauser (1997), whose explicitly declared main goal is to determine the causes underlying variation in natural CSs, human linguistic communication included. Indeed, one should read, as a direct appeal to this framework, the fact that one of the basic assumptions of HCF is that, despite the conspicuous discontinuity among the systems on which communication is based in different species, these systems are nothing else but several instantiations of a unique but highly diversified organic function (Hauser et al. 2002: 1569, especially Figure 1). HCF constitutes, then, no more and no less than an attempt to provide an answer for the particular case of linguistic communication within a broader research agenda seeking the causal factors responsible for the piecemeal diversification of the communicative function in its evolution within different species (Hauser 1997: 1-2).

\section{Language Is Not an ACS ... and Neither Are ACSs}

Taking into account that strictly individual uses are as consubstantial to language as collective uses, that expressions may be externalized or not with the same degree of naturalness, and that externalized expressions may or may not have a truly informative value, without any of these circumstances making them more or less linguistic, Chomsky concludes that language cannot possibly fall within any definition of CS that we may think of (Chomsky 1968: 123). All things considered, accepting that language is an element of the so-called CSs, as is generally assumed both in the Darwinian and the Hauserian versions of the communicative fallacy, looks more like a stipulation inspired by the availability of the notion "animal communication" than a rational decision based on evidence that language is a true member in the class of ACSs.

In fact, this situation is, in our opinion, much more serious and deserving of a more severe criticism than that expressed by Chomsky. It is our contention that language is not, and cannot, be an ACS, because no ACS is in fact an ACS. The reason is clear: the concept "animal communication" does not designate a natural kind. As a consequence, any variety of 
the communicative model suffers from a very serious, foundational problem. In the end, the diversity and discontinuity in the so-called ACSs is easily explained by the fact that no natural unity exists among these systems.

Firstly, it is important to understand that the concept "animal communication" takes us back to the kind of functionalist explanation typical of ethological models. Let us accept, for the sake of the argument, the logic of the functionalist explanation. Modern ethological tradition collects under the tag "animal communication" all forms of behavior implying some contact between organisms through signals made public by some means or other, and to which some informative content and usefulness can be attributed on the basis of its putative connection to the homeostatic equilibrium of the organisms in question. The defining character of the italicized terms in this formulation of the concept is explicitly stated, for example, by Smith (1977: 11-34), a classical perspective on the topic, which we may safely take as representative of the aforementioned application of the ethological tradition to the particular case of communicative behavior. It is also interesting to emphasize the fact that such terms match those on which Chomsky based his thesis of the inappropriateness of linking the scientific study of language to the analysis of the so-called ACSs. As has been pointed out, these terms cannot really be seen as defining in the case of language.

As far as our argument is concerned, we want to focus on the last of these putatively defining terms, according to which every system of communication corresponds to some characteristic kind of usefulness associated with the environmental and populational economy of the organisms employing the system in question. It is a particularly important feature for the ethological model, because, as pointed out by Smith (1977: 16), it has the power to confer an adaptive value to communicative behaviors, and justifies our seeing them as products of natural selection. Should we wish to resort to more modern terminology, we would say that communicative behaviors and the signal systems on which they are based are held to possess a causal function, that is, a relevant role in the homeostatic regime of its practitioners, which eventually refers to a selective function, that is, a historically favorable balance in the reproductive rates of these organisms relative to organisms not instantiating these behaviors and systems (Godfrey-Smith 1994; Griffiths 1994).

Let us not yet discard this functionalist logic. Several species of Old World monkeys call in order to alert their conspecifics to the presence of some predator (Struhsaker 1967; Cheney and Seyfarth 1990: ch. 4). It goes without saying that being alerted is useful, whereas oblivion when some peril is imminent is not; nor can one question the reproductive benefit derived from the possibility of extending one's life a bit more. Males of most avian species sing to attract the attention of females about their qualities (Collins 2004); so one is wrong to deny the benefits of being able to seduce a female, or the reproductive advantages derived from being the winner in such seduction games. We might easily multiply such instances, but it is preferable to stop here, since the examples are too numerous and the ones presented seem to us to suffice. Calling and singing play, for monkeys and birds, a fundamental role in the homeostatic equilibrium in each family of species and, clearly, translate positively in the reproductive rates historically attained by the most successful practitioners of such behaviors. That said and, again, for the sake of the argument, we come to the question that, in our opinion, calls into question the ethological definition of animal communication: if the calls of Cercopithecus aethiops and the songs of Fringillia coelebs are, causally and selectively, natural alert and seduction systems, respectively, what else adds to their functional characterization their further attribution to the communicative function? Our question is rhetorical, of course; and the answer is clearly: nothing.

The case of "communication" is not unique. It is just a particular case of many other ordinary language terms, which cannot survive their transfer to the vocabulary of some theoretical discipline (biology in our case) for the pure and simple reason that they do not denote anything making up a natural kind. For example, Griffiths (1997, 2004a, 2004b) carried out a detailed analysis of this phenomenon with respect to the concept "emotion" in psychology, and his conclusions can be imported, word for word, to the case of "animal communication" in biology: in both the cases, the range of application of the terms is so wide and heterogeneous, and the concurring properties in each case are so diverse that one cannot expect any reliable extrapolations from putative token instances of the category to the category as a whole. All in all, this means that such terms do not implement natural kinds to which either the logic or the practice of scientific discovery can be applied. The case of "animal communication" is particularly representative in this case, since to the aforementioned alarm and seduction systems should be added systems for dissuasion, for spatial representation, for deception, and so on, which, as Griffiths claims should be the case with "emotions," would be better studied independently rather than as instantiations of some superordinate kind. In other words, when we speak of "animal communication" we are not referring to a natural kind, but to a highly heterogeneous collection of behaviors for which there is no hope of finding a sufficient and satisfactory set of common general principles in order to justify a research program. Their reference is "partial": it refers "in part" to alert systems, "in part" to seduction systems, "in part" to deception systems ... just as partial is the reference of many other ordinary language terms, which are useful for a pre-theoretical approach to some theoretical domains, but whose reference cannot ever attain a subjacent natural identity. ${ }^{3}$ 


\section{Against the Functionalist Fallacy}

None of the points we have touched on so far constitutes, however, the main problem for the underpinnings of those frameworks that are based on the communicative fallacy. We would like to point out that a much more severe problem than those discussed so far is the use of the notion "communication" as referring to a phenomenon that is actually independent from the organic structures in which it is manifested and to which the evolution of any complex organic form is inevitably directed. It is, in a nutshell, a conception of communication as an evolutionary a priori of sorts, giving rise to a position where function not only acquires explanatory priority over form but also becomes an independent and transcendental phenomenon whose existence does not presuppose the existence of any form in particular. Since this is a problem affecting not only those models seeking an evolutionary explanation of language in the concept of "communication" but also any evolutionary model whose mode of explanation is strongly based on the notion of "function," we may broaden the range of our criticisms in order to include the latter. We will refer to this mainstream stance in contemporary evolutionary thought as "transcendental functionalism," which, in our opinion, constitutes an insurmountable problem for neo-Darwinian adaptationist approaches.

Think, for example, of the particular case of attributing the function "alarm" to the calls of the different species of Cercopithecidae. Interestingly, a number of species with no close evolutionary connection with these monkeys have developed similar systems of vocalizations discriminating different types of predators and playing the role of collective alarm signals (Griesser 2008). Now, the act of attributing the same function to these behaviors necessarily implies granting this recurring function an existentially autonomous character and the possibility that it may be instantiated in many different species and organic systems - similarly with seduction, spatial representation, or any other function we may deem appropriate to attribute to some collection of organic structures. This is so because the very same criticisms concerning the impossibility of establishing a natural kind capable of including all "communicative functions" are directly applicable to, say, the functions "alarm" or "seduction." Let's take the second of these functions, "seduction," as an example: we immediately see that what typically falls under the label of "seduction" or of "courtship" is in fact a heterogeneous collection of behaviors like courtship feeding (Nisbet 1973), territoriality (Wynne-Edwards 1962; O’Donald 1963), pheromone emission (Thornhill 1992; Moore 1998), construction of artifacts or shelters (McKaye 1979; Borgia 1986; Christy 1988), display of some body part (Petrie et al. 1991), or performance of some kind of dance (Gibson et al. 1991), to which we could add vocalizations, of course, plus some other examples, like the possession of a brightly colored pigmentation or a very long tail (Møller 1994), none of which could hardly be classified as behaviors and which Hauser (1997), for example, includes within the class of "cues." The point is, however, that none (or almost none) of these behaviors or characters is exclusive of "seduction" behavior, as, for instance, ritual dances, which can be associated to "fight" behavior (see Zahavi and Zahavi (1997) for an overview of these and other examples).

All this boils down to the fact that the metaphysics of functions is sufficient to deprive them of any authority at the time of individuating organic structures and establishing the relevant identities to construct evolutionary explanations. As we have noted in connection with the communicative function, no function names a true natural kind (they name, perhaps, something like transcendental kinds), and, as Fodor and Piattelli-Palmarini (2010: part 2, ch. 3) point out, no contingent explanatory law exists if it is not based on actual natural kinds. Besides that, "transcendental functionalism" resorts to a methodology based on a top-down strategy, taking, as we've just argued, a set of "transcendental" and unmistakably "anthropomorphic" categories that are later imposed onto behaviors that, to our eyes, appear to fit them perfectly. ${ }^{4}$

However, functionalism may be dismissed on other grounds, and the case of the evolutionary characterization and explanation of language in functional terms is a particularly good point of departure to criticize another aspect of the "functionalist fallacy." Let's return now to the Chomskyan argument that no use of language exists that may be considered as characteristic: We use language publicly and privately to convey information or to deceive our fellows, to reveal or clarify uncertainty states, with full guarantee, or no actual interest whatsoever, of being understood. Language, as often emphasized by Chomsky (1975: 111, 1980: 240), lacks a "special function," and this is perhaps the only convenient characterization we can come to by making use of a functional vocabulary.

Different authors (e.g., Aitchison 1996; Dunbar 1996) have at some point tried to pinpoint one or another of these functions and, on the grounds of diverse criteria, have identified the function chosen as the special function of language. In most of these cases, this function is put into some relation to or directly identified with the so-called "social uses" of language. Any other uses we make of language, even if consubstantial to its effective way of being, are at most just "parasitic uses" with respect to this essential function.

The problem with these approaches is (at least) twofold. First, criteria like naturalness, frequency of use, or any other putatively useful criterion to determine what is the special function of language are established on strictly stipulative grounds: it is not clear what the valid criterion could be to select the valid criterion (and so on, in an infinite regress). Second, the de facto association of language with a manifold of possible uses or functions poses a problem that Fodor and Piattelli-Palmarini (2010: part 2, ch. 2) identify as endemic 
to any kind of explanation appealing to the different causal roles of coextensive properties. To pinpoint as special a single function from a set of functions while relegating the rest to the status of parasitic requires the use of counterfactuals, that is, of possible alternative situations capable of showing the preservation of the privileged function in the absence of any of the others. But language, let us insist once more on this point, is de facto associated to a manifold of possible uses and functions, and "de facto" here means that language is an organic system that evolved in the world of contingency, within a very specific, and perhaps unique, context, which automatically makes the mechanism that favored its emergence entirely insensitive to counterfactuals.

Moreover, it may well be the case that what appears to be true of language turns out not to be as exceptional as we might think. The call of a vervet monkey, for example, also serves to signal its position within the hierarchy of the group (Cheney and Seyfarth 1990); male finches also sing when they are alone, and, at those times, whatever the purpose of their singing, it certainly is not to seduce a female (White and Teramitsu 2006). Many similar examples could be given. Because if what deserved the unfortunate name of ACSs appear to possess such a high functional specificity, it may be because of our own tendency to see them like this, as a reflex, no doubt, of a more general tendency to see in the morphological and behavioral traits of animals examples of their "exquisite adaptation" to the environmental and populational conditions they live in. Should we free from prejudice our observations of animal behavior, we would probably see "parasitic functions" proliferate and would eventually end up questioning the qualification of "essential function" regarding any of their manifestations.

The conclusion that language lacks a special function should not come as a surprise, then. As argued in Balari and Lorenzo (2010), the conclusion merely maps onto language something that is actually valid for any kind of organic structure: All organic structures are, beyond our natural proclivity to see them as artifacts designed with some specific purpose, functionally nonspecific. Indeed, organic structures possess certain formal or structural properties, which, given the organic and environmental context in which they integrate themselves, endow them with a more or less varied practical potential and, also, a quite variable one from one case to another. Balari and Lorenzo (2010) call this property of organic structures "functionability," emphasizing the fact that it is a strictly formal notion.

All this bears upon the need, emphasized by Love (2007), of distinguishing between the proper activity of an organic structure (its functioning), determined by the internal organizational properties of the structure in question, and the actual use to which it can be put given the organic and environmental context in which it is realized (its usefulness); see Wouters (2003) for some finer distinctions in the characterization and individuation of different types of functions. Thus, as Love (2007) explicates, while the notion of "activity" refers to (or is identifiable with) "how the structure is," the notion of "use" refers instead to "what the structure is for" (pp. 695-696). In this context, the notion of "functionability" may be then defined as the degree of flexibility in the activity of an organic structure, and this is a strictly formal, or, following Love (2007: 701-702), "structural" property and totally underdetermined with respect to the use or the usefulness the said structure may offer to the organism that developed it.

Finally, Balari and Lorenzo (2010) reason that the concept has a clear projection onto the evolutionary arena, in the sense that a high degree of functionability, that is, a high capacity to respond in unexpected ways to organic change and environmental variation may be one of the factors guaranteeing the evolutionary success of a given organic structure. This suggests a connection of the notion of "functionability," which refers to the actual organization state of an organism, with the notion of "adaptability," as defined by Reid (2007) in contraposition to the classical notion of "adaptation." As Reid (2007: 13 and 241) explicitly notes, a high degree of adaptation to specific environmental conditions may turn out to be an evolutionary Catch-22 situation given the essential instability of the medium; but then, a high capacity to formally reconfigure oneself may open to an organism a whole new set of new avenues in order to respond to environmental changes or to move to new environments. Balari and Lorenzo (2010: 76) conclude, then, that "functionability, that is, not being adapted to any environment (medium or context) in particular and having the ability to function in new and unexpected manners, is one of the keys to evolutionary success" [our translation].

\section{Homology and Development: Two Key Concepts for an Evolutionary Explanation of Language}

These considerations suggest that a key concept for an adequate evolutionary explanation for any organic system is that of "homology," whose original formulation still offers an appropriate point of departure for the application of this notion in the case of language- - "HomologuE: The same organ in different animals under every variety of form and function" (Owen 1843: 379). From this simple definition we clearly see the reason why none of the versions of the communicative model can in any case lead us to an adequate explanation of the evolutionary origins of language: The functional identity or diversity one may attribute to organic structures is entirely detached from their actual commonality of origin and evolutionary diversification. This means, for example, that no matter how similar what a bird does when singing or what a monkey does when calling may seem to us with what a human does when speaking, such similarity is not necessarily an indication of a common origin or a diversification history from 
some primeval structure with a similar function. One of the main lessons to be learned from the comparative study of organisms, wherefrom the concept of homology emerged in the 19 th century, concerns precisely the evidence for the enormous variety of functions the "same" structure may serve in different organic and environmental contexts (Owen 1849).

As we pointed out in the introduction, some attempts have been made to extend the notion of homology to the realm of behavior and function. A classical example is that of Hodos (1976), where the following definition of homologous behaviors is provided: "Behaviors are considered homologous to the extent that they can be related to specific structures that can, in principle, be traced back through a genealogical series to a stipulated ancestral precursor irrespective of morphological similarity" (p. 156). According to this definition, Hodos analyzes the case of the forelimbs of mammals and the wings of birds and concludes that, inasmuch as these structures have a common phyletic origin, "any behaviors that involve use of wings and use of forelimbs are homologous, at least as movements." It is interesting to dwell upon this conclusion by Hodos because, on the one hand, it implicitly points to a variety of Love's (2007) notion of proper activity of an organic structure; on the other hand, however, the attempt to extend the concept of homology beyond the strict range of structure introduces a rather counterintuitive idea with respect to what common sense appears to tell us about the movement of living beings, at least since Aristotle's writings on the topic, namely that the activity we call "movement" in mammals, reptiles, and birds is not the same activity as what we call "movement" in fish, crustaceans, or mollusks. ${ }^{5}$ It is not our goal to defend Aristotle and to attack Hodos, nor do we wish to consolidate or undermine intuitions. We simply want to stand fast on the fact that just because a phenomenon may appear to us humans to be an observable element of nature (such as, for instance, movement or communication, or the movement or the communication of amniotes), it does not necessarily follow that it in fact corresponds to a natural category deserving its incorporation in scientific theory. In other words, Aristotle's intuition that movement is "one" (but also the Hodosian version that it may be "several") perhaps tells us something about how the human mind perceives and categorizes the world, but does not necessarily tell us anything about the world this mind is trying to explain. We must therefore be prepared to eliminate from our theories these types of constructs (such as functions and even, perhaps, behaviors), which are nothing else but a product of our minds.

Perhaps to avoid the kinds of problems pointed out above, some other authors have argued that behavior can be the subject matter of homological relations irrespective of a given structural base. For instance, Greene (1994) contends that homology is not a quality of certain biological traits (say, anatomical traits), with the exclusion of others (say, behavioral traits).
He argues that once the monophyletic character of a certain clade has been firmly established, every resemblance at any given level of biological analysis (anatomical, behavioral, and so on) can be deemed a posteriori a homology. It is, however, doubtful, as we have argued above, that behavior is the locus of real evolutionary change (see also Klopfer 1973), and since "homology" is just a particular category of evolutionary explanations, it is doubtful that this category is relevant at the behavioral level. Note also that Greene's (1994) position is incompatible with the existence of the so-called "deep" (or "across-clades"; Shubin et al. 1997, 2009) homologies, a contention that is entirely at odds with our own conclusions, as will be seen below. ${ }^{6}$

The main lessons to be learned from the preceding discussion with respect to human language are clear. Language deserves to be treated just like any other organic structure and put into a specific relation with other organic structures, independent of the usefulness each structure may have. We must be prepared to see language related to structures whose uses have little or no relation whatsoever with the uses to which we normally put language; also, and above all, we must be prepared to ignore the uses of language as well as any other structure that our evolutionary explanation hypothesizes, and eventually reveals, to be homologous to language.

It is important to note that Owen's definition presents homology as a variety of identity that is also independent of the formal diversity observed in the "same" structure. Homology does not consist—or, better, does not consist exactly—in some kind of formal identity between things. This is particularly relevant for the case of language, whose apparent exceptionality in formal terms has traditionally been highlighted as the main reason to consider it an exceptional system, that is, one with no real homologues in the organic world (e.g., Chomsky 1968: 124, 2000: 51-52). However, Owen's definition, which we want to retain, although with some qualifications, makes us think that language might well have true homologues in other organisms, although with a formal divergence comparable, for example, to the differences between the forelimbs of humans and those of manatees.

The preceding discussion suggests, therefore, that the main question one should address before applying the concept of homology to the evolutionary study of language is that of establishing the kind of subjacent identity, according to which the different homologues of a structure are taken as varieties "of form and function." Following the analysis of Padian (2008: 1vii), in Owen's notion of "homology," there converge three different but complementary criteria for identity: a positional criterion, a histological criterion, and an ontogenetic criterion, with the first being the privileged one and the remaining two having only an ancillary role (see also Amundson 2008; Rupke 1994). As for 20th-century biology, however, the tendency has been that of emphasizing what may be seen as 
an equivalent to Owen's ontogenetic criterion, namely what eventually came to be known as the "biological concept of homology" (Wagner 1989a, 1989b). The main motivation for this move is, naturally, connected to the explosion of knowledge about the mechanisms of organic development since Owen's time, and also the firm belief that such factors as position and histology may present such a high degree of variability that trusting them may eventually prevent the real appreciation of a close evolutionary relation between two compared structures. Wagner (1989a, 1989b) estimates, however, that, despite their propensity to vary, the affinity of mechanisms participating in the definition during development of the individuality and identity of structures within the organic framework of which they are an integral part is a much more reliable criterion than its organization and composition, and that this should therefore be the prevailing criterion at the time of providing a biological concept of homology (also see Hall 1994).

Before we definitively turn to the particular case of language, we would like to add that from his precise distinction between the notions of "activity" and "use" of organic structures discussed above, Love (2007) concludes that the first of these notions, given its eminently structural and nonfunctional character, may be employed in a nonproblematic way as a possible criterion on which homology can be based in different organic systems. Since the mode of action of some organic system is just another dimension of, and therefore almost indistinguishable from, the way its components are organized, this point of view strikes us as entirely coincident with the ideas we presented at the end of the previous section in connection with those developed by Balari and Lorenzo (2010).

That said, we can conclude that the attribution of homologues to any kind of organic system is a task that may be carried out by resort to several different strategies, which may be related to organizational-structural features of the system (its components, the relative disposition with respect to each other, etc.), or to the kinds of activities such organization gives rise to (but without paying special attention to their usefulness from the point of view of their relation to other organic systems or the environment), or to the mechanisms on which the establishment of their individuality and identity during development is based (ideally, in a broader sense than that of mere genomic comparison). Moreover, we understand that these are not mutually excluding strategies, but rather converging ones, capable of joining forces aiming to reveal homology relations even with the tougher cases. In the case of language, the relative lack and reliability of data that can be associated to each of these strategies may in fact be compensated by the high degree of congruence observed among them (Lorenzo 2010).

Let us then turn to language and dwell for a while on a recently discovered relation between the mechanisms regulating the development of some of the brain structures subserving language and the brain structures subserving the learning and performance of birdsong in some avian species. It is a fairly well-known story, but it may be convenient to briefly review it.

In 2001, the identification of the first gene (FOXP2) unequivocally related to language development in humans was announced. Since then, an important volume of data has been gathered concerning the expression of this gene in the brain, particularly in the basal ganglia, the cerebellum, and the frontal cortex, about its implication in the development of other organic structures, about the complex regulation network in which it participates, and about its evolutionary history, which has revealed the highly conservative character of the gene. ${ }^{7}$

Besides this, a homologous gene (FoxP2) has been identified in birds, associated in some species with the development of socially induced birdsong. Also, its has been possible to verify that such function is fundamentally connected to the levels of expression of the gene in the so-called area X, a component of the anterior brain circuit associated with the learning of a birdsong. This circuit is part of a structure in birds that is homologous with basal ganglia in humans, where, as pointed out above, FOXP2 is also expressed. In these species of birds, birdsong plays the role of a call from males as well as a stimulus for hormonal and behavioral availability of females with respect to sex and maternity. ${ }^{8}$ Now, do these data allow us to conclude that birdsong is a true homologue of language in humans?

It is hardly possible to give this question a simple yes or no answer, without qualifications, but if pressed to do so, we would say: no, this datum does not confirm the idea that language derives from some ancestral form of call like the one imagined by Darwin, because neither does this datum disconfirm that what organisms do is not itself something that evolves per se. We hope to elucidate this in the following paragraphs.

Firstly, is the participation of two homologous genes (FOXP2 and FoxP2) enough for us to conclude that the structures in the differentiation of which these genes play a role are themselves homologous? Evidently, the answer can only be that this is certainly a hint that they are, but just a hint and an insufficient one at that. There are two reasons for that answer. On the one hand, pleiotropy is in fact more the norm than the exception. In principle, that these genes correlate with language and birdsong is no guarantee that the structures subserving one and the other skill are actual homologues. On the other hand, these are regulatory genes, and, while data already exist about the "target genes" on which FOXP2 acts, it is not yet possible to say anything about the degree of overlapping between the regulatory cascade in which it participates with respect to language and the corresponding chain in which FoxP2 participates with respect to a birdsong.

In any case, and secondly, we do know that both genes express themselves in partially overlapping brain structures, and 
in particular, in some specific areas within the basal ganglia. Now, Lieberman (2006) characterized this structure, from the point of view of the kind of activity it performs, as a "repetitive sequential machine," which operates when we walk, talk, or make up certain kinds of thoughts. Our claim is then that, irrespective of use, one can establish a parallelism between the computational structures and activities that in the organic contexts of birds and humans correlate, respectively, with birdsong and language. This is not to mean, however, that language and birdsong are homologous skills, even though there most probably exists homology at the level of the computational (or combinatorial) structures and activities subjacent to these skills. Nevertheless, this makes birdsong and language neither diversified versions of the same ancestral (communicative) skill nor particular instantiations of the same natural phenomenon (communication). Indeed, the proposed homology relation would still hold if the computational system and activity were related, in another organic context, to an activity not even remotely connected to anything close to what we intuitively call communication. For example, this could in fact be the very same system that some species of birds put to use in the complex computational process involved in the act of nest building (Collias and Collias 1962; Hansell 2000; Balari and Lorenzo 2008, 2009).

Therefore, the homology relation we are defending here is based on the congruence between the resources deployed during development and the organization/activity of the resulting structures. We've already pointed out that our knowledge concerning the former is still fragmentary, and, as we will presently make clear, the anatomical correspondence between these putatively homologous systems is, in fact, incomplete. It is nevertheless important to remember that "homology" is an identity relation between nonequals and, consequently, such incompleteness in correspondence is to be expected precisely due to the evolutionary diversification of the structure.

Finally, from the anatomical point of view, there is no clear correspondence between the brain components that, in each case, play the role of the necessary working memory space to carry out the computations. In the case of humans, it seems reasonable to suppose that this role is played by certain cortical circuits in which Broca's area appears to occupy a central position, but also with projections toward certain frontal and parietotemporal areas (Balari and Lorenzo 2008, 2009). Birds do possess an analogous structure to the neo-cortex, while the structure playing a similar role appears to be what is known as the "dorsal ventricular crest," considered to be a homologue of amygdala and claustrum in mammals (Striedter 2005). These observations appear to break in a nontrivial manner the parallelism between the natural computational systems attributed to each species. Our idea is, however, that the incorporation of the said cortical circuits to the working memory component represents the true innovation of the system, whose alterations during development in the particular case of humans acted as critical factors at the time of facilitating access to the level of computational complexity required to process linguistic expressions. As argued in Balari and Lorenzo (2008, 2009), such a scenario would correspond to the co-occurrence of a number of instances of heterochrony by late termination or hypermorphosis (Gould 1977), in the sense that the overdevelopment of the cortex would have favored the implementation, in the human brain, of a memory system with the necessary capacity and structure to deal with sequences in a linear fashion, but also hierarchically and at an arbitrary distance; that is, the implementation in the human brain of a context-sensitive natural computational system. ${ }^{9}$

All this is, of course, highly speculative, but we believe it represents an important point of departure to tackle many unsolved issues concerning the evolutionary explanation of language. Here we will summarize them as a conclusion to this section.

Firstly, language does not conform a natural kind with any other ability, communicative or otherwise. It is based, however, on the activity of a natural computational system, shared with many other species (perhaps a universal or quasiuniversal one among vertebrates), which nevertheless use it for many different tasks by plugging into other systems and within different environmental conditions in each case. It is therefore licit to talk of homology at the level of analysis where the organization/activity of this system is captured, but not at other levels (i.e., what organisms do) where other similarities suggested by the analysis do not correspond to a real identity resulting from a common origin.

Secondly, language possesses a number of unique features (perhaps specifically linguistic, but this is an empirical question), but from this it doesn't necessarily follow that its evolution was totally independent from other animal capacities. Language is the product of some developmental system $(D)$, a variety of the developmental systems $(d)$ responsible for the implementation in other species' brains of computational systems homologous to the linguistic system. From the evolutionary point of view, the most distinctive features of $D$ appear to be (1) the incorporation of the cortex to the memory component of the system; and (2) the overdevelopment of this component as a consequence of the extension of a number of phases within human cortical development. Also, point (2) seems to be related to the fact that the kinds of complex computations made possible by the system facilitate the human act of talking, instead of just singing, calling, or building shelters.

Finally, to the question "does language have specific components?," it seems that one can only answer in an alternatively positive and negative way. The positive side concerns the attained phenotype: no other species talks; the negative one concerns the developmental system capable of producing such a 
phenotype: contrary to what seems at first sight to be the case, plenty of its homologues populate the organic world. It may well be the case that the question turns out not to be so crucial and clarifying at the time of tackling the problem of language evolution. Perhaps this is so because the "specific/shared" dichotomy is not as theoretically clear as it seems to be. Our point of view is that the only biologically sensible answers to the questions are those derived from an analysis based on the concepts of homology and development.

\section{Conclusion}

To conclude, then, it is hopeless to keep on trying to base the evolutionary explanation of language on functional parallelisms with other organic structures or on trivial formal comparisons between them. It is imperative to start basing it on the establishment of parallelisms and divergences at the level of the subjacent generative mechanisms acting during the development of organic structures (Gould 2002). This is, by the way, the type of explanation that makes reasonable our identification as homologues of language certain biological systems in organisms with a relatively distant evolutionary relation to humans (deep homology) despite the fact that such systems show different practical applications with little or no relation at all with what is typically known as communication or with other uses we may give to language. The existence of extremely old and relatively conservative developmental systems that are fairly extensive in the organic world is one of the strongest assets of contemporary evolutionary developmental biology (Hall 1999; Carroll 2005; Minelli 2009). Our proposal boils down to nothing more (and nothing less) than linking language to one of these systems, granting it a long evolutionary history, and explaining its fairly recent emergence as a result of the modifications effected to such a system.

\section{Acknowledgments}

This work has been carried out through the project "Biolingüística: Fundamento genético, desarrollo y evolución del lenguaje" (HUM200760427/FILO) of the Spanish Ministerio de Ciencia e Innovación and partially cofunded by FEDER funds (Balari and Lorenzo), and received support from the Generalitat de Catalunya through grant 2009SGR1079 to the Universitat Autònoma de Barcelona (Balari). We would like to thank Cedric Boeckx for his very helpful suggestions on an earlier version of this article. All remaining errors are our own.

\section{Notes}

1. See, in particular, Darwin ([1871] 1879: 106-114). For a reconstruction of the Darwinian argument and some comments on its (limited) validity, see Lorenzo (2010).

2. An illustrative example of these contemporary attempts of keeping alive the Darwinian version of the communicative fallacy can be found in Újhelyi (1996, 1998).
3. The fuzziness of behavior was an accepted fact by (logical) behaviorists, which Wittgenstein ([1953] 1988: $\S 66 \mathrm{ff}$ ) captured with his notion of "family resemblance," and this is precisely the reason why behaviorism always tried to draw a distinction between central and peripheral instances of behavior. Chomsky (1969) presents a very similar argument to the one we are offering here and in the following section, and concludes that this focus on mere description "avoids any attempt at explanation" (Chomsky 1969: 281).

4. See Kennedy (1992) for similar criticisms, although Kennedy's recipe against anthropomorphism points to a radically different direction from ours.

5. As Aristotle explicitly put it:

Elsewhere we have investigated in detail the movement of animals after their various kinds, the differences between them, and the reasons for their particular characters (for some animals fly, some swim, some walk, others move in various other ways); there remains an investigation of the common ground of any sort of animal movement whatsoever. (De motu animalium, 698a 1-5; this English translation by A.S.L. Farquharson is available at http://classics .mit.edu/).

6. Space prevents us from presenting a more detailed analysis of the notion of "behavioral homology" here; suffice it to say that for evolutionary psychology, in the tradition of sociobiology and behavioral ecology, this has never been an issue. As John Maynard-Smith put it in his comments to Greene (1999): "We probably reacted a little too strongly against the fascination that people like Konrad Lorenz had in the homology of different behaviors" (p. 183). For traditional ethology it was an issue, and this is the position we criticize in the text.

7. See Benítez-Burraco (2009) and references cited therein for a comprehensive and up-to-date overview of data concerning FOXP2.

8. See Balari and Lorenzo $(2008,2009)$ for details and references, and an extension of some ideas sketched in the text.

9. The analysis of birdsong in terms of its computational complexity reveals a level of complexity always within finite-state systems (Todt and Hultsch 1998; Okanoya 2002).

\section{References}

Aitchison J (1996) The Seeds of Speech: Language Origin and Evolution. Cambridge: Cambridge University Press.

Amundson R (2008) Richard Owen and animal form. In: On the Nature of Limbs (Owen R; Amundson R, ed), xv-lii. Chicago: University of Chicago Press.

Balari S, Lorenzo G (2008) Pere Alberch's developmental morphospaces and the evolution of cognition. Biological Theory 3: 297-304.

Balari S, Lorenzo G (2009) Computational phenotypes: Where the theory of computation meets Evo-Devo. Biolinguistics 3: 2-61.

Balari S, Lorenzo G (2010) ¿Para qué sirve un ballestrinque? Reflexiones sobre el funcionamiento de artefactos y organismos en un mundo sin funciones. Teorema: Revista Internacional de Filosofía 29(1): 5776.

Benítez-Burraco A (2009) Genes y Lenguaje. Aspectos Ontogenéticos, Filogenéticos y Cognitivos. Barcelona: Reverté.

Borgia G (1986) Sexual selection in bowerbirds. Scientific American 254: $70-79$.

Carroll SB (2005) Endless Forms Most Beautiful: The New Science of EvoDevo. New York: Norton.

Cheney DL, Seyfarth RM (1990) How Monkeys See the World: Inside the Mind of Another Species. Chicago: University of Chicago Press.

Chomsky N (1968) Language and Mind. New York: Harcourt Brace Jovanovich. 
Chomsky N (1969) Some empirical assumptions in modern philosophy of language. In: Philosophy, Science, and Method (Morgenbesser S, Suppes P, White M, eds), 260-285. New York: St. Martin's Press.

Chomsky N (1975) Reflections on Language. New York: Pantheon Books.

Chomsky N (1980) Rules and Representations. New York: Columbia University Press.

Chomsky N (2000) The Architecture of Language. New Delhi, India: Oxford University Press.

Christy JH (1988) Pillar function in the fiddler crab Uca beebei. II: Competitive courtship signaling. Ethology 78: 113-128.

Collias NE, Collias EC (1962) An experimental study of the mechanisms of nest building in a weaverbird. The Auk 79: 568-595.

Collins S (2004) Vocal fighting: the functions of birdsong. In: Nature's Music (Marler PR, Slabbekoorn H, eds), 39-79. San Diego, CA: Elsevier Academic Press.

Darwin C ([1871] 1879) The Descent of Man, and Selection in Relation to Sex, 2nd ed. London: John Murray. [2004 (James Moore J, Desmond A, eds). London: Penguin Classics.]

Dunbar R (1996) Grooming, Gossip, and the Evolution of Language. Cambridge, MA: Harvard University Press.

Eibl-Eibesfeldt I ([1984] 1993) Die Biologie des menschlichen Verhaltnes: Grundriss der Humanethologie (tr. into Spanish by Giner Abati F, Cencillo L). Madrid: Alianza.

Fodor JA, Piattelli-Palmarini M (2010) What Darwin Got Wrong. New York: Farrar, Straus and Giroux.

Gibson RM, Bradbury JW, Vehrencamp SL (1991) Mate choices in lekking sage grouse revisited: The roles of vocal display, female site fidelity and copying. Behavioral Ecology 2: 162-180.

Godfrey-Smith P (1994) A modern theory of functions. Noûs 28: 344 362.

Gould SJ (1977) Ontogeny and Phylogeny. Cambridge, MA: The Belknap Press.

Gould SJ (2002) The Structure of Evolutionary Theory. Cambridge, MA: The Belknap Press.

Greene HW (1994) Homology and behavioral repertoires. In: Homology: The Hierarchical Basis of Comparative Biology (Hall BK, ed), 369-391. San Diego, CA: Academic Press.

Greene HW (1999) Natural history and behavioural homology. In: Homology (Bock GR, Cardew G, eds), 173-188. Chichester, England: John Wiley/Novartis Foundation.

Griesser M (2008) Referential calls signal predator behavior in a group-living bird species. Current Biology 18: 69-73.

Griffiths PE (1994) Cladistic classification and functional explanation. Philosophy of Science 61: 206-227.

Griffiths PE (1997) What Emotions Really Are: The Problem of Psychological Categories. Chicago: University of Chicago Press.

Griffiths PE (2004a) Is emotion a natural kind? In: Philosophers on Emotion (Solomon R, ed), 233-249. Oxford: Oxford University Press.

Griffiths PE (2004b) Emotions as natural and normative kinds. Philosophy of Science 71: 901-911.

Hall BK, ed (1994) Homology: The Hierarchical Basis of Comparative Biology. San Diego, CA: Academic Press.

Hall BK (1999) Evolutionary Developmental Biology, 2nd ed. Dordrecht, the Netherlands: Kluwer.

Hansell MK (2000) Bird Nests and Construction Behaviour. Cambridge: Cambridge University Press.

Hauser MD (1997) The Evolution of Communication. Cambridge, MA: Harvard University Press.

Hauser MD, Chomsky N, Fitch T (2002) The faculty of language: What is it, who has it, and how did it evolve? Science 298: 15691579 .
Hodos W (1976) The concept of homology and the evolution of behavior. In: Evolution, Brain, and Behavior: Persistent Problems (Masterton RB, Hodos W, Jerison H, eds), 153-167. Hillsdale, NJ: Lawrence Erlbaum.

Kennedy JS (1992) The New Anthropomorphism. Cambridge: Cambridge University Press.

Klopfer PH (1973) Does behavior evolve? Annals of the New York Academy of Sciences 223: 113-125.

Lieberman P (2006) Toward an Evolutionary Biology of Language. Cambridge, MA: Harvard University Press.

Lorenzo G (2010) Devo-Darwinismo. Lo que el lenguaje nos enseña sobre el papel del desarrollo en la evolución natural. Éndoxa 24: 247274.

Love AC (2007) Functional homology and homology of function: Biological concepts and philosophical consequences. Biology and Philosophy 22: 691-708.

McKaye KR (1979) Sexual selection and the evolution of cichlid fishes of Lake Malawi. In: Cichlid Fishes' Behaviour, Ecology and Evolution (Keenleyside MHA, ed), 241-257. London: Chapman and Hall.

Minelli A (2009) Forms of Becoming. Princeton, NJ: Princeton University Press.

Møller AP (1994) Sexual Selection and the Barn-Swallow. Oxford: Oxford University Press.

Moore AJ (1998) Female preferences, male social status, and sexual selection in Nauphoeta cinerea. Animal Behavior 36: 303-305.

Nisbet ICT (1973) Courtship feeding, egg size and breeding success in common terns. Nature 241: 141-142.

O'Donald P (1963) Sexual selection and territorial behaviour. Heredity 18: 361-364.

Okanoya K (2002) Sexual display as a syntactic vehicle: The evolution of syntax in birdsong and human language through sexual selection. In: The Transition to Language (Wray A, ed), 46-64. Oxford: Oxford University Press.

Owen R (1843) Lectures on the Anatomy and Physiology of the Invertebrate Animals. London: Longman, Brown, Green, and Longmans.

Owen R (1849) On the Nature of Limbs. London: John Van Voorst.

Padian K (2008) Richard's Owen Quadrophenia. The pull of opposing forces in Victorian cosmogony. In: On the Nature of Limbs (Owen R, Amundson R, eds), liii-xcii. Chicago: University of Chicago Press.

Petrie M, Halliday T, Sanders C (1991) Peahens prefer peacocks with elaborate trains. Animal Behavior 41: 323-331.

Reid RGB (2007) Biological Emergences. Evolution by Natural Experiment. Cambridge, MA: MIT Press.

Rupke N (1994) Richard Owen. Victorian Naturalist. New Haven, CT: Yale University Press.

Shubin N, Tabin C, Carroll S (1997) Fossils, genes and the evolution of animal limbs. Nature 388: 639-648.

Shubin N, Tabin C, Carroll S (2009) Deep homology and the origins of evolutionary novelty. Nature 457: 818-823.

Smith JW (1977) The Behavior of Communicating: An Ethological Approach. Cambridge, MA: Harvard University Press.

Striedter GF (2005) Principles of Brain Evolution. Sunderland, MA: Sinauer.

Struhsaker TT (1967) Auditory communication among vervet monkeys (Cercopithecus aethiops). In: Social Communication Among Primates (Altmann SA, ed), 1197-1203. Chicago: University of Chicago Press.

Todt D, Hultsch H (1998) How songbirds deal with large amounts of serial information: Retrieval rules suggest a hierarchical song memory. Biological Cybernetics 79: 487-500.

Thornhill R (1992) Female preference for the pheromone of males with low fluctuating asymmetry in the Japanese scorpionfly (Panorpa japonica, Mecoptera). Behavioral Ecology 3: 277-283. 
Újhelyi M (1996) Is there any intermediate stage between animal communication and language? Journal of Theoretical Biology 180: 71-76.

Újhelyi M (1998) Long-call structure in apes as a possible precursor for language. In: Approaches to the Evolution of Language: Social and Cognitive Bases (Hurford JR, Studdert-Kennedy M, Knight C, eds), 177-189. Cambridge: Cambridge University Press.

Wagner GP (1989a) The biological homology concept. Annual Review of Ecology and Systematics 20: 51-69.

Wagner GP (1989b) The origin of morphological characters and the biological basis of homology. Evolution 43: 1157-1171.
White S, Teramitsu I (2006) FoxP2 regulation during unidirected singing in adult songbirds. Journal of Neuroscience 26: 7390-7394.

Wittgenstein L ([1953] 1988) Philosophische Untersuchungen. Barcelona: Crítica. [Bilingual ed.]

Wouters A (2003) Four notions of biological function. Studies in History of Philosophy of Biology and Biomedical Sciences 34: 633-668.

Wynne-Edwards VC (1962) Animal Dispersion in Relation to Social Behaviour. Edinburgh: Oliver and Boyd.

Zahavi A, Zahavi A (1997) The Handicap Principle: A Missing Piece of Darwin's Puzzle. Oxford: Oxford University Press. 